\title{
Anemia in prospective blood donors deferred by the copper sulphate technique of hemoglobin estimation
}

\author{
Samuel Antwi-Baffour ${ }^{1 *}$, David Kwasie Annor ${ }^{1}$, Jonathan Kofi Adjei ${ }^{1 \dagger}$, Ransford Kyeremeh ${ }^{1 \dagger}$, George Kpentey ${ }^{2 \dagger}$ \\ and Foster Kyei ${ }^{3+}$
}

\begin{abstract}
Background: Patients who require transfusion as part of their clinical management have the right to expect sufficient blood to be available to meet their needs and to receive the safest blood possible. Donor deferrals (disqualification) lead to loss of precious blood donors and blood units available for transfusion purposes. It is believed that a large majority of donor deferrals are due to temporal and correctable causes such as anemia in developing countries. It is therefore important to determine anemia among donor population to inform decision-making on the type of measures to be taken to reduce deferrals due to anemia. The aim of the study was to determine anemia in prospective blood donors deferred by the copper sulphate technique of hemoglobin estimation. This, to provide information that would help plan a future strategy for donor recruitment and management.

Methods: Three (3) ml of venous blood samples were collected from the study subjects into EDTA anticoagulant tubes. The hemoglobin levels and red cell indices were measured using Sysmex hematology analyser. A thin blood film was prepared and stained using Leishman stain and then observed under the light microscope.

Results: The prevalence of anemia among the total deferred patients (538) was $17.1 \%$. Four different types of anemia were found among the subjects. These were normocytic normochromic (46.74\%), microcytic hypochromic (42.39\%) normocytic hypochromic (8.70 \%), and microcytic normochromic anemia (2.17\%).

Conclusion: The study showed that a significant number of the prospective blood donors deferred for having low hemoglobin by the copper sulphate method turned out to have anemia by the standard method of diagnosis. Prevalence of anemia among apparently healthy blood donors was therefore higher than expected. Measures must therefore be taken to address this in order not to lose potential blood donors due to a correctable and preventable cause such as anemia.
\end{abstract}

Keywords: Anemia, Blood donors, Blood transfusion, Donor deferrals, Hemoglobin

\section{Background}

Blood transfusion is an essential part of health care. It contributes to saving millions of lives each year in both routine and emergency situations [1]. It permits increasingly complex medical and surgical interventions and dramatically increases the life expectancy and quality of life of patients with a variety of acute and chronic conditions $[1,2]$. To make blood transfusion safe for patients,

\footnotetext{
*Correspondence: s.antwi-baffour@chs.edu.gh

${ }^{\dagger}$ Equal contributors

'Department of Medical Laboratory Sciences, School of Biomedical and Allied Health Sciences, College of Health Sciences, University of Ghana, P. O. Box KB 143, Korle-Bu, Accra, Ghana

Full list of author information is available at the end of the article
}

many safety measures are undertaken by the blood transfusion community and the most important is the selection of blood donors [2]. Blood donor suitability standards are based on science, informed medical opinion, and regulatory rules. These are criteria designed to protect both the donor and the recipient [3]. Individuals disqualified from donating blood are known as "deferred" donors and they are deferred for various reasons [3].

Deferrals can be categorized as temporary short term (1-56 days), temporary long term (57-365 days), and multiple years/permanent (more than 365 days) [4]. The key to recruiting and retaining safe blood donors is good epidemiological data on the prevalence and incidence, 
where possible, of infectious markers in the population which help to identify low-risk donor populations. Also, a satisfying experience during blood donation, good donor care and effective communication between blood donation centre staff and blood donors are all essential factors for the retention of safe blood donors [1]. The deferral of blood donors is a painful and sad experience for the blood donor as well as the blood donation centre screening the donor. These deferrals "bleed" the donor-recruiting efforts of a blood centre, wasting efforts to gain new donors. Moreover, deferring prospective donors often leaves them with negative feelings about themselves as well as the blood donation process [5]. Additionally these donors are less likely to return for blood donation in the future [6].

In developing countries, it is believed that a large majority of donor deferral could be due to a temporal and correctable cause such as anemia which is a condition of less than normal levels of healthy red blood cells circulating in the blood stream [7]. The severity of anemia is measured by a person's hemoglobin level and the causes could be nutritional (e.g. iron) deficiency, haemorrhage, decreased synthesis of red blood cells or hemoglobin, and so on $[8,9]$. Most donor centres use the copper sulphate method to estimate blood levels and defer those who fail the test. However, not all these people may be truly anemic. It is therefore important to determine anemia amongst them using the standard diagnostic method so that those found to be truly anemic could be advised on measures required to treat and prevent the anemia.

The truth is, estimates of anemia prevalence by themselves are only useful if they are associated with a picture of the various causal factors that contribute to the development of the anemia in specific settings $[10,11]$. Indeed these factors are multiple and complex and it is critical to collect accurate information about them to provide the basis for developing the best interventions for anemia control $[12,13]$. The overall objective of this study was to determine anemia using standard diagnostic methods in prospective blood donors deferred as a result of failing to attain the expected blood levels required using the copper sulphate technique. The outcome is expected to show who among those deferred was truly anaemic and what type of anemia they have. This will help in the planning of future strategies for donor recruitment and management.

\section{Methods}

\section{Study design}

This study was a cross sectional study carried out in June 2012.

\section{Study population}

The subjects were consenting potential blood donors who failed to meet the requirement for donation due to low hemoglobin level using the copper sulphate technique.

\section{Ethical consideration}

Ethical clearance for this research was sought from the Ethics and Protocol Review Committee at the School of Biomedical and Allied Health Sciences, University of Ghana, Legon. All the participants gave their informed consent before their samples were collected.

\section{Materials}

Some of the materials used include: Hematology analyser (Sysmex 2000i), Sysmex cell pack and stromatolyser, $5 \mathrm{ml}$ $\mathrm{K}_{2}$ EDTA test tubes and Light Microscope.

\section{Sample collection and analysis}

Three millilitres $(3 \mathrm{ml})$ of blood sample was collected from each of the subject into Ethylene Diamine TetraAcetic acid (EDTA) anticoagulant test tube. The samples were then sent to the laboratory within $4 \mathrm{~h}$ of collection to be analysed on the hematology analyzer (Sysmex 2000i). Thin blood film was prepared and stained using Leishman stain for morphologic assessment of the red blood cells. The film was then examined under the light microscope using $\times 40$ objective to select a good area for examination and then a drop of oil placed on the film and examined with the $\times 100$ objective.

\section{Data analysis}

The statistical analysis of the data was done using the Statistical Package for Social Sciences (SPSS) version 16.0. Data was represented as frequency Tables and graphs. Pearson's correlation was used to test the relationship between the various variables that was measured as well as the characteristics of the respondents.

\section{Results}

A total number of 1263 prospective blood donors presented to donate blood during the period of this study. Out of these, 1120 (88.68\%) were males and $143(11.32 \%)$ females. A total of 538 (42.6 \%) involving 444 males and 94 females were deferred due to varied reasons and $114(21.2 \%)$ of these were due to low hemoglobin $(\mathrm{Hb})$ level. These were assessed for anemia using $\mathrm{Hb}$ and red cell indices from a hematology autoanalyser and morphology. Those with $\mathrm{Hb}<13.5$ for males and $\mathrm{Hb}<12.0$ for females were termed as anemic. Ninety two (92) forming $80.7 \%$ of the 114 were eventually diagnosed with various forms of anemia using the standard methods (FBC and morphology). This represented $17.1 \%$ of the total number (538) deferred and $7.3 \%$ of the total (1263) prospective donors (Table 1). Twenty two (22) forming $19.3 \%$ of those who failed the copper sulphate test were found not to be anemic.

The mean age of the 114 (68 males and 46 females) deferred donors due to low blood levels was 30 years 
Table 1 A Table of participant's profiles, mean and standard deviation of the $\mathrm{Hb}$ concentrations and the frequencies of the severity of anemias detected

\begin{tabular}{|c|c|c|c|}
\hline PARAMETERS & MALES & FEMALES & $\overline{\text { TOTAL }}$ \\
\hline Number of donors & $1120(88.68 \%)$ & $143(11.32 \%)$ & 1263 \\
\hline Number of deferrals & 444 & 94 & 538 \\
\hline Number of deferrals due to low $\mathrm{Hb}$ by $\mathrm{CuSO}_{4}$ & 68 & 46 & 114 \\
\hline Minimum $\mathrm{Hb}(\mathrm{g} / \mathrm{dl})$ & 7.1 & 7.7 & \\
\hline Maximum $\mathrm{Hb}(\mathrm{g} / \mathrm{dl})$ & 14.7 & 12.9 & \\
\hline Mean $\mathrm{Hb}+/-\mathrm{SD}$ & $11.9 / 1.6$ & $11.0 / 1.2$ & \\
\hline Mild anemia (Hb 10.0-13.5g/dl) & 44 & 33 & 77 \\
\hline Moderate anemia $(\mathrm{Hb} 7.0-10.0 \mathrm{~g} / \mathrm{dl})$ & 9 & 6 & 15 \\
\hline
\end{tabular}

From the Table, it shows that the number of male donors surpassed that of females by a wide margin, but among those deferred for low Hb, the numbers were not that wide apart. The males also recorded both the lowest and highest $\mathrm{Hb}$ levels. It can also be seen that a greater number of participants had mild anemia in comparison to moderate anemia

with majority of them between $21-30$ years. The mean $\mathrm{Hb}$ concentration and standard deviation of both males and females was $11.5 \mathrm{~g} / \mathrm{dl} \pm 1.5$ as well as Frequencies of the severity of anemia in both sexes are all shown in Table 1. The distribution of hemoglobin concentration is shown in Fig. 1.

Four different types of anemia based on the red cell indices and morphology studies were found in the participants who were diagnosed with anemia. These were normocytic normochromic, normocytic hypochromic, microcytic normochromic and microcytic hypochromic. Comparative analysis of gender and age distribution against the types of anemia was also done and no correlation was established (Table 2). Also analysed was the distribution of the types of anemia in relation to the severity. Majority of the respondents who had mild anemia had normocytic normochromic anemia (51.95\%), while the rest had microcytic hypochromic anemia (35.06\%), normocytic hypochromic anemia (10.39\%) and microcytic normochromic anemia (2.60\%). Majority of those who had moderate anemia had microcytic hypochromic anemia $(80.00 \%)$ and the rest had normocytic normochromic anemia (20.00 \%) (Fig. 2).

\section{Discussion}

In spite of the many programs and interventions undertaken by the various national blood transfusion services, blood transfusion service centres continues to be unsuccessful in their efforts to maintain required stock levels of blood. A lot of potential donors are deferred for reasons which are sometimes temporal (e.g. low $\mathrm{Hb}$ level) and majority of these donors do not return to the centre again. This study established that the deferral rate among blood donors was significantly high (42.6\%) of which low hemoglobin levels by $\mathrm{CuSO}_{4}$ formed $21.2 \%$. This rate varies from the findings of a study in India which had total deferral rate of $11.5 \%$ of which $15.5 \%$ was due to anemia which incidentally compares well with the $17.1 \%$ obtained in our study $[14,15]$.

Our study discovered four types of anemia based on the red cell indices and blood morphology. These were normocytic normochromic, normocytic hypochromic, microcytic normochromic and microcytic hypochromic anemia. The types of anemia with the highest frequency were normocytic normochromic anemia (46.7 \%) and microcytic hypochromic anemia (42.4\%). The findings also showed that the prevalence of

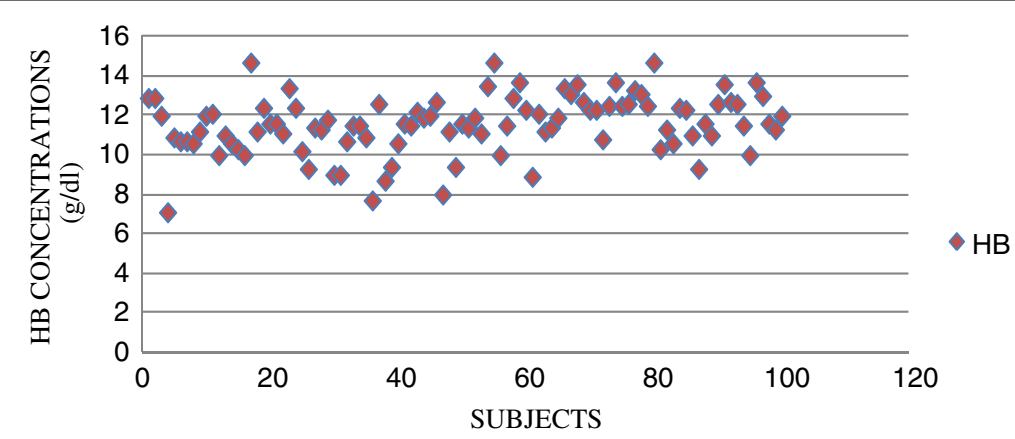

Fig. 1 Diagram showing the distribution of hemoglobin concentrations 
Table 2 Distribution of the types of anemia in relation to gender and age of participants

\begin{tabular}{|c|c|c|c|c|c|c|}
\hline \multicolumn{2}{|l|}{ Type of anemia } & \multirow{2}{*}{$\begin{array}{l}\text { Normocytic } \\
\text { normochromic } \\
27\end{array}$} & \multirow{2}{*}{$\begin{array}{l}\text { Microcytic } \\
\text { hypochromic } \\
20\end{array}$} & \multirow{2}{*}{$\begin{array}{l}\text { Microcytic } \\
\text { normochromic } \\
1\end{array}$} & \multirow{2}{*}{$\begin{array}{l}\begin{array}{l}\text { Normocytic } \\
\text { hypochromic }\end{array} \\
5\end{array}$} & \multirow{2}{*}{\begin{tabular}{|l} 
Total \\
53
\end{tabular}} \\
\hline Sex & Males & & & & & \\
\hline & Females & 16 & 19 & 1 & 3 & 39 \\
\hline \multirow[t]{9}{*}{ Age cate-gory } & $<20$ & 5 & 1 & 1 & 1 & 8 \\
\hline & $21-25$ & 8 & 11 & 1 & 3 & 23 \\
\hline & $26-30$ & 13 & 10 & 0 & 2 & 25 \\
\hline & $31-35$ & 8 & 8 & 0 & 1 & 17 \\
\hline & $36-40$ & 3 & 7 & 0 & 1 & 11 \\
\hline & $41-45$ & 4 & 1 & 0 & 0 & 5 \\
\hline & $46-50$ & 1 & 0 & 0 & 0 & 1 \\
\hline & $51-55$ & 1 & 0 & 0 & 0 & 1 \\
\hline & $56-60$ & 0 & 1 & 0 & 0 & 1 \\
\hline
\end{tabular}

It can be seen from the Table that a greater number of the participants presented with Normocytic normochromic, followed by Microcytic hypochromic, Normocytic hypochromic and lastly Microcytic normochromic. Age category of 26-30 had the highest number of anemia cases

anemia was significantly higher in female donors than males. Again, $83.7 \%$ out of the 92 diagnosed with anemia presented with mild anemia against $16.3 \%$ with moderate anemia [16]. This means that most of them can have their blood levels improved in a short period of time with proper advice and medication making it possible to return at a later date to donate [17].

Furthermore, statistical analysis (Table 2) showed no relationship between gender and type of anemia $(p>0.05)$, neither was there a relationship between the age and type of anemia $(p>0.05)$. Also, there was no relationship between the ages of the respondents and the severity of anemia $(p>0.05)$ and between the gender of the respondents and the severity of anemia $(p>0.05)$. The lack of relationship between these parameters could be as a result of the fact that the respondents were apparently healthy individuals who had passed the same criteria for selection for donation as healthy individuals prior to blood level estimation. The results of the study however, showed significant relationship between the severity of anemia and the type of anemia $(p<0.05)$.

The findings from our study would help blood collection centres to plan a future strategy for donor recruitment and management by using the standard method to

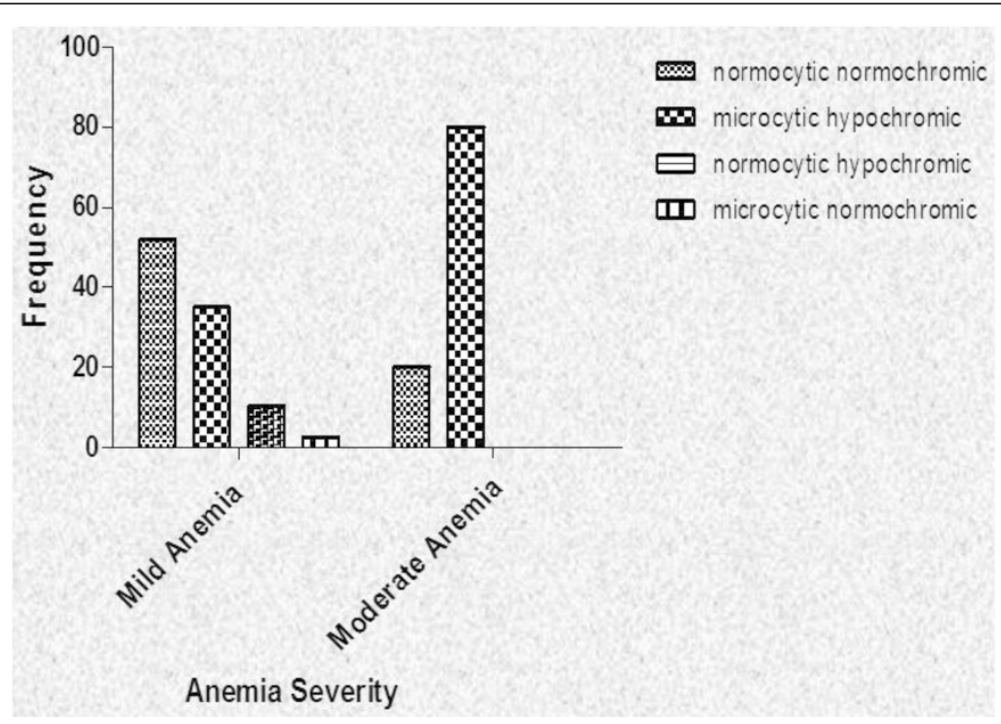

Fig. 2 A graph of the distribution of the types of anemia in relation to the severity of the anemia. The participants who were diagnosed with anemia were categorised into mild anemia group with the $\mathrm{Hb}$ concentration of $10.0-13.5 \mathrm{~g} / \mathrm{dl}$ and moderate anemia with $\mathrm{Hb}$ concentration of $7.0-10.0 \mathrm{~g} / \mathrm{dl}$. From Fig. 2 , it can be seen that majority of those with moderate anemia had microcytic hypochromic anemia with the rest presenting with normocytic normochromic type. On the other hand, those with mild anemia had a fair distribution except for the microcytic normochromic group 
test potential donors who fail the copper sulphate procedure of $\mathrm{Hb}$ estimation. This way, people who would be found truly anemic can be assisted to improve their condition with informed advice and medication so they can return to donate. Again, those found to be falsely low can then go ahead and donate. In general, it will help blood collection centres to develop and implement strategies and tactics to manage blood donors well and to evaluate the effectiveness of programs and services as far as donor safety is concern. Subsequently they will be able to support the delivery, sustainment and growth of donor recruitment and retention $[18,19]$.

Furthermore, the outcome will also assist in formulating a policy guidance on providing blood donor counselling as an essential component of quality donor service and care and as a requirement for a safe blood supply. The counselling of blood donors is an important means of promoting healthy lifestyles and makes an important contribution to individual and community health [20]. In addition, counselling contributes to the early diagnosis and treatment of conditions such as anemia, blood disorders and infections which will offer a crucial early entry point for the treatment and care of donors found to be unfit $[21,22]$. Counselling may also reduce adverse donor reactions, improve donor perceptions of the blood transfusion services and, most importantly, increase the likelihood of them returning for future donation [23]. This way, donor deferrals or lost particularly due to anemia may be reduced.

\section{Conclusion}

There was a high prevalence of deferral of prospective blood donors and a significant proportion of these deferred donors were as a result of low $\mathrm{Hb}$ levels and subsequently anemia. Normocytic normochromic anemia and microcytic hypochromic anemia were the most common type of anemia detected. Most of them had mild anemia which can be reversed in a short period of time if the necessary advice and treatment is given. It can therefore be concluded that people who fail the copper sulphate procedure of $\mathrm{Hb}$ testing should not be just sent way as deferred donors but rather be assessed for anemia and be offered advice and treatment so that if their anemia can be corrected, they are encouraged to come back to donate.

\footnotetext{
Abbreviations

$\mathrm{CuSO}_{4}$ : Copper sulphate; EDTA: Ethylene Diamine Tetra-Acetic acid; FBC: Full Blood Count; Hb: Hemoglobin; RBC: Red Blood Cell; RDW: Red Cell

Distribution Width; WBC: White Blood Cell; WHO: World Health Organization.
}

\section{Competing interests}

We the authors of this manuscript declare that none of us as authors of this paper has any conflict of interest in relation to this manuscript.

\section{Authors' contributions}

$S A B$ participated in the design, co-supervised the research and drafted the manuscript. DKA participated in the design of the study and carried out the experimental work. JKA, RK, GK and FK participated equally in the supervision of the work and proof reading of the manuscript. All authors read and approved the final manuscript.

\section{Acknowledgements}

We are grateful to Prof. Patrick F. Ayeh-Kumi the Dean of the School of Biomedical and Allied Health Sciences (SBAHS), College of Health Sciences, University of Ghana for his assistance in the development and drafting of the manuscript. We will also like to acknowledge the following persons for their help in putting the manuscript together: Dr. I.A Bello, Dr. Charles Brown and Mr. David Nana Adjei, all of SBAHS.

\section{Author details}

'Department of Medical Laboratory Sciences, School of Biomedical and Allied Health Sciences, College of Health Sciences, University of Ghana, P. O. Box KB 143, Korle-Bu, Accra, Ghana. ${ }^{2}$ The Central Medical Laboratories, Korle-bu Teaching Hospital, Accra, Ghana. ${ }^{3}$ College of Agriculture and Natural Sciences, School of Biological Sciences, Department of Molecular Biology and Biotechnology, University of Cape Coast, Cape Coast, Ghana.

Received: 23 May 2015 Accepted: 8 October 2015

Published online: 22 October 2015

\section{References}

1. WHO 2010. Towards $100 \%$ voluntary blood donation: a global framework for action. Geneva: WHO press.

2. Sundar P, Sangeetha SK, Seema DM, Marimuthu P, Shivanna N. Pre-donation deferral of blood donors in South Indian set-up: An analysis. Asian J Transfus Sci. 2010;4(2):112-5.

3. Newman B. Blood donor suitability and allogeneic whole blood donation. Transfus Med Rev. 2001;15(3):234-44.

4. Arslan $\mathrm{O}$. Whole blood donor deferral rate and characteristics of the Turkish population. Transfus Med. 2007;17(5):379-83.

5. Brecher ME. AABB Technical Manual. 15th Edition. Bethedsa, MD: AABB press; 2005. p. 101

6. Custer B, Chinn A, Hirschler NV, Busch MP, Murphy EL. The consequences of temporary deferral on future whole blood donation. Transfusion. 2007;47(8):1514-23.

7. McLean E, Cogswell M, Egli I, Wojdyla D, de Benoist B. Worldwide prevalence of anaemia, WHO Vitamin and Mineral Nutrition Information System, 1993-2005. Public Health Nutr. 2009;12(4):444-54.

8. Urrechaga E, Hoffmann JJML, Escanero JF. From Wintrobe to the XXI century. A Story of Inspiration and Effort, Int J Translation Community Dis. 2014;02(04):37-41.

9. Bach V, Schruckmayer G, Sam I, Kemmler G, Stauder R. Prevalence and possible causes of anemia in the elderly: a cross-sectional analysis of a large European university hospital cohort. Clin Interv Aging. 2014;9:1187-96.

10. Rahim F. Microcytic hypochromic anemia patients with thalassaemia: Genotyping approach. Indian J Med Sci. 2009;63(3):101-8.

11. Green R. Anemias beyond B12 and iron deficiency: the buzz about other B's, elementary, and non elementary problems. ASH Education Book -. Hematology. 2012;2012(1):492-8.

12. Eivazi-Ziaei J, Dastgiri S, Pourebrahim S, Soltanpour R. Usefulness of red blood cell flags in diagnosing and differentiating thalassemia trait from iron-deficiency anemia. Hematology. 2008;13(4):253-6.

13. Rathod DA, Kaur A, Patel V, Patel K, Kabrawala R, Patel M, et al. Usefulness of cell counter-based parameters and formulas in detection of betathalassemia trait in areas of high prevalence. Am J Clin Pathol. 2007;128(4):585-9.

14. Bahadur S, Pujani M, Jain M. Donor deferral due to anemia: A tertiary care center-based study. Asian J Transfus Sci. 2011;5(1):53-5.

15. Spivak JL. Anemia in the elderly: time for new blood in old vessels? Arch Intern Med. 2005;165(19):2187-9.

16. Kariyeva GK, Magtymova A, Sharman A. Demographic and Health Surveys: Chapter 12: Anemia. [Internet document available from http:// dhsprogram.com/pubs/pdf/fr130/12chapter12.pdf. accessed 2.9.2015]. 
17. World Health Organization. Iron deficiency anaemia: assessment, prevention, and control: a guide for programme managers. Geneva, Switzerland: World Health Organization; 2001.

18. Newman BH. Adjusting our management of female blood donors: the key to an adequate blood supply. Transfusion. 2004;44:591-6.

19. Rabeya Y, Rapiaah M, Rosline H, Ahmed SA, Zaidah WA, Roshan TM. Blood pre - donation deferrals - a tertiary hospital Experience. Southeast Asian J Trop Med Public Health. 2008;39:571-4.

20. Davey RJ. The blood centre as a community health resource. Vox Sang. 2006;91(3):206-13.

21. Delaney MK et al. Blood center practice and education for blood donors with anemia. Transfusion. 2011;51(5):929-36.

22. Allain JP et al. Deferred donor care in a regional hospital blood center in Ghana. Transfusion. 2009;49(4):669-75.

23. Reiss RF. Blood donor well-being: a primary responsibility of blood collection agencies. Ann Clin Lab Sci. 2011;41(1):3-7.

\section{Submit your next manuscript to BioMed Central and take full advantage of:}

- Convenient online submission

- Thorough peer review

- No space constraints or color figure charges

- Immediate publication on acceptance

- Inclusion in PubMed, CAS, Scopus and Google Scholar

- Research which is freely available for redistribution 